\title{
SGLT 2 inhibitor induced euglycemic ketoacidosis
}

\author{
Dhivahar G. ${ }^{1}$, Balasubramanian S. ${ }^{2}$, Raghunath D. ${ }^{3}$, Misra S. ${ }^{*}$ \\ DOI: https://doi.org/10.17511/ijoso.2020.i01.12
}

1 Dhivahar G., Consultant, Department of Critical Care Medicine, GEM Hospital and Research Center, Coimbatore, Tamil Nadu, India.

2 Shankar Balasubramanian, Registrar, Department of Surgical gastroenterology, GEM Hospital and Research Center, Coimbatore, Tamil Nadu, India.

3 Raghunath D., Consultant, Department of Critical Care Medicine, GEM Hospital and Research Center, Coimbatore, Tamil Nadu, India.

4* Shivanshu Misra, Consultant Surgical Gastroenterologist and Advanced Laparoscopic Surgeon, GEM Hospital and Research Center, Coimbatore, Tamil Nadu, India. https://orcid.org/0000-0001-5160-6211

SGLT2 inhibitors are being increasingly prescribed for the treatment of type 2 diabetes mellitus. Apart from lowering HbA1c, they are also potentially beneficial in reducing body weight and blood pressure. The awareness among Indian doctors of the potentially fatal complication of SGLT2 inhibitor induced diabetic ketoacidosis may not be widespread. To complicate things further, the blood glucose levels may not be as high as would be expected in a case of diabetic ketoacidosis, making the diagnosis more challenging. We present a case of empagliflozin induced euglycemic ketoacidosis in a post Whipple's surgery patient. A 52 years old man with upper abdominal pain was found to have a duodenal mass on evaluation. He was a known diabetic on tablets sitagliptin and empagliflozin. Patient underwent Whipple's surgery for the duodenal mass. Patient had severe metabolic acidosis with ketosis in the immediate post-operative period with mild elevation of blood sugar. The common causes of ketoacidosis were eliminated and the diagnosis of drug induced ketoacidosis was clinched. Patient was successfully treated with intravenous fluids, dextrose and insulin infusion and discharged in good health.

Keywords: Empagliflozin, Euglycemic ketoacidosis, SGLT2 inhibitor, Whipple's surgery

Corresponding Author

Shivanshu Misra, Consultant Surgical

Gastroenterologist and Advanced Laparoscopic

Surgeon, GEM Hospital and Research Center,

Coimbatore, Tamil Nadu, India.

Email: shivanshu_medico@rediffmail.com
How to Cite this Article

To Browse

Dhivahar G, Balasubramanian S, Raghunath D, Misra

S. SGLT 2 inhibitor induced euglycemic ketoacidosis.

Surgical Review Int J Surg Trauma Orthoped. 2020;6(1):64-66.

Available From

https://surgical.medresearch.in/index.php/ijoso/artic le/view/153

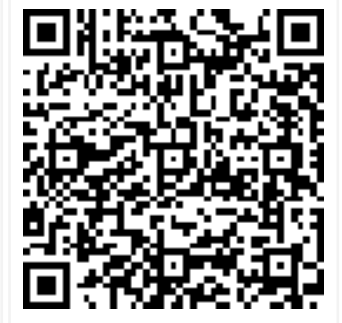

\section{Introduction}

SGLT2 inhibitors are being increasingly prescribed for the treatment of type 2 diabetes mellitus. Apart from lowering HbA1c, they are also potentially beneficial in reducing body weight and blood pressure. Empagliflozin
04-01-2020

Conflict of Interest No

Review Round 1
$14-01-2020$
Funding
Nil

Review Round 2

Ethical Approval
Was further found to be effective in cardiovascular risk reduction and lowering mortality. Another potential benefit of this group of drugs is that, they act through insulin independent mechanisms to lower blood glucose levels. Though very effective in the treatment of diabetes, they have been

(c) 2020 by Dhivahar G., Shankar Balasubramanian, Raghunath D., Shivanshu Misra and Published by Siddharth Health Research and Social Welfare Society. This is an Open Access article licensed under a Creative Commons Attribution 4.0 International License https://creativecommons.org/licenses/by/4.0/ unported [CC BY 4.0].

Accepted 27-01-2020 Note 
Associated with a potentially life-threatening complication of diabetic ketoacidosis. This complication can occur even in patients with type 2 diabetes. Moreover, ketoacidosis may be seen even when the blood glucose level is less than $200 \mathrm{mg} / \mathrm{dL}$ $[1,2]$.

India has a huge burden of diabetes with a prevalence of over 72 million in 2017 as estimated by International Diabetes Federation. SGLT2 inhibitors have been approved for the treatment of type 2 diabetes and are effective in regulating HbA1c levels.

SGLT2 inhibitors exert their glucose lowering action by blocking SGLT2, a sodium-glucose co-transporter protein in the proximal convoluted tubule in the kidneys thereby preventing reabsorption of glucose. This mechanism of action is insulin independent and has a low risk of precipitating hypoglycaemia.

\section{Case Report}

A 52 years old gentleman presented with complaints of on and off upper abdominal pain associated with nausea and vomiting for three months. There was no history of heartburns or regurgitation. There was no history of fever or jaundice associated with the pain.

Patient had no bowel or bladder symptoms. His appetite was preserved and there was no obvious weight loss. He was a known diabetic on tablet sitagliptin $100 \mathrm{mg}$ once daily and tablet empagliflozin $10 \mathrm{mg}$ once daily with good glycaemic control.

He had no other co-morbidities. Contrast CT scan of the abdomen showed hypodense lesion in the medial wall of second part of duodenum and head of pancreas. His complete blood count, blood sugar, $\mathrm{HbA1c}$, kidney and liver function tests were within normal limits. Patient underwent Whipple's surgery for the duodenal mass. The operation was uneventful. Patient had ketoacidosis in the postoperative period. His blood pressure was $120 / 60$ $\mathrm{mm} \mathrm{Hg}$, pulse rate was $130 / \mathrm{min}$ and sPO2 was $99 \%$ with $\mathrm{FIO} 2$ of $40 \%$.

Arterial blood gas analysis showed the following: $\mathrm{pH}-7.29, \mathrm{pCO}-27.5 \mathrm{~mm} \mathrm{Hg}, \mathrm{pO}-212 \mathrm{mmHg}$, bicarbonate-12.7 mmol/L. His blood glucose level was $183 \mathrm{mg} / \mathrm{dL}$ and blood ketone were $4.5 \mathrm{mmol} / \mathrm{L}$. His serum calcium was $4.26 \mathrm{mg} / \mathrm{dL}$. Other common causes of ketoacidosis were excluded. A diagnosis of empagliflozin induced diabetic ketoacidosis was eventually made.
Treatment: The patient was treated aggressively with intravenous fluids, glucose and insulin infusion. Patient responded well to the treatment. His ketoacidosis gradually settled down. He was discharged in good health a week later after giving proper advice about the possible adverse effects of this drug.

\section{Discussion}

They are however, associated with a potentially lifethreatening adverse effect of diabetic ketoacidosis. The US FDA issued a drug safety communication in May 2015 stating that these drugs can be associated with diabetic ketoacidosis. SGLT2 inhibitors by causing glycosuria reduce insulin secretion. The reduced insulin glucagon ratio favors ketogenesis and can eventually precipitate ketoacidosis [3-6].

Bonora et al estimated the incidence of SGLT2 inhibitor induced ketoacdosis to be less than $1 / 1000$ person-years from various randomised controlled trials. It is interesting to note that ketoacidosis associated with these drugs may not always be associated with high levels of blood glucose typical of diabetic ketoacidosis. In fact, blood glucose in our patient was only $183 \mathrm{mg} / \mathrm{dL}$. This is of clinical significance as the diagnosis could easily be missed if one is not aware of such an adverse effect $[7,8]$.

The time interval from the initiation of drug therapy to the onset of diabetic ketoacidosis is extremely variable. Also, some of the patients who developed ketoacidosis were wrongly diagnosed as having type 2 diabetes while in fact they had type 1 diabetes making them more prone to develop ketoacidosis. Bonora et al recommend testing for auto antibodies before initiating therapy with SGLT2 inhibitors to rule out type 1 diabetes $[1,3]$.

It is also advisable to stop SGLT2 inhibitors in patients undergoing emergency surgeries and hold the medication 24 hours prior to planned surgeries and switch over to insulin-based regimen during the perioperative period. Prolonged starvation should be avoided.

If the patient is kept nil per oral prior to surgery, intravenous administration of dextrose containing IV fluids must be advised to minimize the possibility of precipitation of ketoacidosis. The treatment for SGLT2 inhibitor induced ketoacidosis is similar to diabetic ketoacidosis involving aggressive rehydration and insulin therapy even when the blood glucose level is not very high $[9,10]$. 


\section{Conclusion}

Both the patient and the treating physician should be aware of this dreaded adverse effect so that it can be recognized in a timely fashion and treated appropriately.

\section{Acknowledgements}

The authors like to thank the hospital surgical and pathology department as well as the patient for all their help for preparing this article.

\section{Reference}

01. Bonora BM, Avogaro A, Fadini GP. Sodiumglucose co-transporter-2 inhibitors and diabetic ketoacidosis- An updated review of the literature. Diabetes Obes Metab. 2018;20(1)2533.

doi: [Article:https://doi.org/10.1111/dom.13012] [Crossref]

02. Zinman B, Wanner C, Lachin JM, Fitchett D, Bluhmki $E$, Hantel $S$ et al. Empagliflozin, cardiovascular outcomes, and mortality in type 2 diabetes. N Engl J Med. 2015;373;2117-2128. doi:

[Article:https://doi.org/10.1056/NEJMoa1504720] [Crossref]

03. US Food and Drug Administration. Drug Safety Communication- FDA revises labels of SGLT2 inhibitors for diabetes to include warnings about too much acid in the blood and serious urinary tract infections. US Food and Drug Administration. 2015.

Available at: [Article:https://www.fda.gov/Drugs/DrugSafety/ucm4 75463.htm][Crossref]

04. Kalra S. Sodium glucose co-transporter 2 inhibitors- a review of their basic and clinical pharmacology. Diabetes Ther. 2014;5(2);355366.

doi: [Article:https://doi.org/10.1007/s13300-0140089-4][Crossref]

05. Nauck MA. Update on developments with SGLT2 inhibitors in the management of type 2 diabetes. Drug Des Devel Ther. 2014;8;13351380 .

doi:

[Article:https://dx.doi.org/10.2147\%2FDDDT.S50773 ][Crossref]
06. Turner J, Begum T, Smalligan RD. Canagliflozininduced diabetic ketoacidosis. J Investig Med High Impact Case Rep. 2016;4(3);2324709616663231.

doi:

[Article:https://doi.org/10.1177/2324709616663231] [Crossref]

07. Candelario N, Wykretowicz J. The DKA that wasn't- a case of euglycemic diabetic ketoacidosis due to empagliflozin. Oxf Med Case Reports. 2016;7;144-146.

doi:

[Article:https://dx.doi.org/10.1093\%2Fomcr\%2Fomw 061][Crossref]

08. Pfutzner A, Klonoff D, Heinemann L, Ejskjaer N, Pickup J. Euglycemic ketosis in patients with type 2 diabetes on SGLT2-inhibitor therapy- an emerging problem and solutions offered by diabetes technology. Endocrine. 2017;56(1)212216.

doi: [Article:https://doi.org/10.1007/s12020-0171264-y][Crossref]

09. Rosenstock J, Ferrannini E. Euglycemic diabetic ketoacidosis- a predictable, detectable, and preventable safety concern with SGLT2 inhibitors. Diabetes Care. 2015;38(9)16381642.

doi: [Article:https://doi.org/10.2337/dc15-1380] [Crossref]

10. Duggan EW, Carlson K, Umpierrez GE. Perioperative hyperglycemia management- an update. Anesthesiol. 2017;126(3)547-560. [Article:https://doi.org/10.1097/ALN.0000000000001 515][Crossref] 